\title{
Uspešnost sinhroniziranja nekaterih animiranih filmov z jezikoslovčevega vidika
}

\author{
Mira KrajnC Ivič \\ Univerza v Mariboru, Filozofska fakulteta, Koroška cesta 160, \\ SI-2000Maribor,mira.krajnc@uni-mb.si
}

\begin{abstract}
Prispevek prikazuje nezanemarljive razlike med podnaslovnimi prevodi, ki večinoma upoštevajo slovensko jezikovno normo in predpis, ter sinhronizacijo, ki poustvarja način govorjenja »doma« oz. tvorjenje ožjeinteresnih dvogovorov, torej vključuje tako obrobne kot tudi ekscesne sociolekte, upošteva skladenjske značilnosti govorjenih besedil, večja je ekspresivnost tudi kot posledica številnih aktualizacij frazemov, besedilnega in okoliščinskega namigovanja, znanega pretežno slovenskim naslovnikom.
\end{abstract}

The paper establishes significant differences between subtitles, which mostly observe the Slovene linguistic code and synchronization, which recreates the spoken word as it is used in everyday situations with characteristics typical of spoken discourse; thus, marginal and excessive sociolects and unfinished syntactic structures, discourse markers, changes in word order etc. are included. Synchronization is more expressive than subtitles because of its actualization of idioms, text and context allusions known to Slovenian recipients.

Ključne besede: slovenski jezik, govorjeni diskurz, dvogovor, sinhronizacija

Key words: Slovene language, spoken discourse, dialogue, synchronization

\section{Uvod}

O uspešnosti sinhronizacije - po Zakonu o javni rabi slovenščine določen način prevoda za tujejezične igrane ali risane/animirane filme, namenjene predšolskim otrokom - bi morali presojati njihovi prvotni naslovniki, torej predšolski otroci. Uveljavljena praksa med ustvarjalci teh filmov pa je filme oblikovati 
zanimive za kar najširšo publiko. ${ }^{1}$ Kot mama petletnika imam priložnost opazovati reakcije naslovnika ob spremljanju risanih filmov, mišljeni sta predvsem vztrajanje pred zanimivim risanim filmom ali izguba zanimanja, popuščanje koncentracije. Ti reakciji sta jasna pokazatelja, kako uspešna je produkcija, na to $\mathrm{v}$ veliki meri vpliva tudi sinhronizacija, določenega filma. Po drugi strani pa kot jezikoslovka skušam razumeti uspešnost sinhroniziranja risanega filma v smislu jezikovne pragmatike in sociolingvistike interakcije: katera jezikovna sredstva je izbral tvorec za doseganje svoje namere glede na jezikovno, kulturno, družbeno in drugače specifičnega naslovnika, ter z vidika (ne)upoštevanja razlik med značilnostmi govorjenih in zapisanih sporočil.

\section{Gradivo}

$\mathrm{Za}$ analizo sem si izbrala novejše tujejezične, večinoma ameriške animirane filme: Avtomobili (Cars, 2006), Ratatouille (2007), Divji valovi (Surf's Up, 2007), Ninja želve (Teenage Mutant Ninja Turtles, 2007) in zgoščenko z najlepšimi svetovnimi pravljicami Mitološki junaki pravljic.

\section{Analiza gradiva}

Za ugotavljanje uspešnosti sinhroniziranja risanih filmov z jezikovnopragmatičnega vidika in tudi z vidika sociolingvistike interakcije je treba najprej opisati sporočanjske okoliščine. Tvorec, tj. avtor režiser risanega filma s pomočjo likov, ki jim glasove v izvirniku vedno pogosteje posojajo znani in uveljavljeni igralci, skuša podobno kot avtorji (pisci in ilustratorji) slikanic v določenem razmerju med jezikovnim (besedilnim) in nejezikovnim (okoliščinskim) tipom informacije sporočiti: predstaviti imaginarno, a verjetno in prvotnim naslovnikom dopadljivo zgodbo. $Z$ njo želi vplivati na otroke - pa tudi na drugo kar najširšo publiko -, da se ob gledanju zabavajo in sprostijo ali pa v zgodbi najdejo nauk ter motivacijo za reševanje svojih težav. Prav zato naj bi osrednji lik omogočal poistovetenje. Osrednji liki v risanih filmih Avtomobili, Divji valovi in Ratatouille so: dirkalnik Strela McQueen, pingvin Cody Maverick in podgana Remy, ki se svoje drugačnosti zavedajo in imajo prav zaradi nje težave. Življenje jih postavi na preizkušnjo, iz katere odidejo bogatejši in srečnejši, saj spoznajo, da je drugačnost tudi dobra. ${ }^{2} \mathrm{~V}$ Ninja želvah je v ospredju boj med dobrim in zlim, poudarjena pa je bratska složnost med glavnimi liki Leonardom, Raphaelom, Donatellom in Michelangelom. Na zgoščenki Mitološki junaki pravljic so predstavljene znane zgodbe: zgodba o egipčanskem

\footnotetext{
${ }^{1}$ Zato risane filme, kamor sodijo tudi filmi, izbrani za analizo, oglašujejo kot družinske pustolovščine.

${ }^{2}$ Podobno je zasnovan Bevkov Peter Klepec. To je zgodba o drobižku, ki dobi nadnaravno moč, da lahko premaga tiste, ki so grdo ravnali z njim, in pomaga pomoči potrebnim.
} 
princu Mojzesu, o pomorščaku Sinbadu, o Ali babi in štiridesetih razbojnikih ter zgodba o Herkulu ter zlatem jabolku.

Izbor zgodbe je tesno povezan s tvorčevo, režiserjevo namero. Ta je pozivna, povezovalna, poetska, saj lahko funkcijo igranih risanih filmov do določene mere primerjamo s funkcijo, ki jo ima otroška, mladinska literatura, in poučna: zgodbe vsebujejo pomembno spoznanje ali nauk. Tako npr. v animiranem filmu Divji valovi liki razmišljajo o tem, kdo je zmagovalec (a), v Ratatouille pa o spremembah in vdanosti v usodo (b).

(a) »Vidijo svoj cilj in gredo drzno proti njemu, pa ne zaradi denarja ali pa slave /.../ Tekmujejo zaradi užitka, navdušenja /.../; To je tisti, ki najbolj uživa na dili.«

(b) Django: »Tako pač je. Ne moreš spreminjati narave.« - Remy: »Spremembe so del narave. In na to lahko vplivamo. Začne pa se, ko se sami tako odločimo."

Pri sinhroniziranju ostaja okoliščinski tip informacije - izvzet je naslovnik in vse, kar je povezano z njim - nespremenjen, spremeni se jezikovni oz. besedilni tip, saj se spremeni jezikovni kod: namesto angleščine se uporabi slovenščina. Tako je ugotavljanje uspešnosti sinhroniziranja z vidika jezikoslovca po eni strani stvar dobrega prevoda, tu mislim predvsem, ali se je prevajalec uspel čim bolj približati dejansko sporočenemu v izvirniku - merilo bi lahko bila ilokucijska moč izrečenega -, po drugi strani pa, ali se je uspel čim bolj približati načinu govorjenja likov glede na način govorjenja oz. tvorjenja govorjenih besedil, sporočil, značilen za slovenščino, tj. kako uspešen je film pri nagovarjanju slovenske publike.

\subsection{Uspešnost sinhroniziranja - uspešnost prevodov}

Prvi vidik uspešnosti, torej uspešnost prevodov, ni predmet podrobne analize, zgolj za ponazoritev problematike navajam tabelo 1 .

Tabela 1: Uspešnost prevodov v risanem filmu Divji valovi

\begin{tabular}{|c|c|c|c|c|}
\hline \multicolumn{3}{|c|}{ Besedilni tip informacije } & \multirow{3}{*}{$\begin{array}{l}\text { Okoliščinski tip } \\
\text { informacije }\end{array}$} & \multirow{3}{*}{$\begin{array}{l}\text { Komentiranje in interpretacija } \\
\text { sporočenega }\end{array}$} \\
\hline \multirow{2}{*}{$\begin{array}{l}\text { Angle- } \\
\text { ško }\end{array}$} & \multicolumn{2}{|c|}{ Slovensko } & & \\
\hline & $\begin{array}{l}\text { Podnapi- } \\
\text { sano }\end{array}$ & $\begin{array}{l}\text { Govor- } \\
\text { jeno }\end{array}$ & & \\
\hline $\begin{array}{l}\text { Keep } \\
\text { your } \\
\text { girl- } \\
\text { friend } \\
\text { out of } \\
\text { this. }\end{array}$ & $\begin{array}{l}\text { Svoje pun- } \\
\text { ce ne vple- } \\
\text { taj v to. }\end{array}$ & $\begin{array}{l}\text { Ti pa } \\
\text { odsrfaj, } \\
\text { kura. }\end{array}$ & $\begin{array}{l}\text { Sporočevalec je Tank, } \\
\text { predmet govora pa } \\
\text { petelinček Joe, nanj se } \\
\text { nanašata izraza girl- } \\
\text { friend in svoja punca. } \\
\text { Pri govorjenem se nanj } \\
\text { nanašata drugoosebni } \\
\text { edninski zaimek ti, ki je } \\
\text { v zvalniškem pastavku } \\
\text { konkretiziran s kura. }\end{array}$ & $\begin{array}{l}\text { Ker se le pri govorjenem Tank neposre- } \\
\text { dno obrne na petelinčka Joeja, sicer na } \\
\text { Codyja, se ilokucijska moč izrečenega ne } \\
\text { spremeni. V obeh primerih gre za žalitev, } \\
\text { katere učinek je dosežen z metaforo: } \\
\text { petelin (moški) je kura/kokoš (ženska). Pri } \\
\text { tem se zdi, da je izraz kura v primerjavi } \\
\text { z izrazom kokoš v smislu negativnosti } \\
\text { ekspresivnejši. }\end{array}$ \\
\hline
\end{tabular}




\begin{tabular}{|c|c|c|c|c|}
\hline $\begin{array}{l}\text { Why } \\
\text { don't } \\
\text { you } \\
\text { work } \\
\text { on my } \\
\text { glutes a } \\
\text { little bit? } \\
\text { That's } \\
\text { very } \\
\text { nice. }\end{array}$ & $\begin{array}{l}\text { Še rit mi } \\
\text { zmasiraj } \\
\text { malo. O, } \\
\text { kako to } \\
\text { paše. }\end{array}$ & $\begin{array}{l}\text { Dej mi še } \\
\text { malo rit } \\
\text { zmasiri. } \\
\text { Če } \\
\text { prdnem, } \\
\text { te odnese. }\end{array}$ & $\begin{array}{l}\text { Izrečeno je Tankova } \\
\text { reakcija na Codyja, ko } \\
\text { se ta jezi nanj, ker Tank } \\
\text { po Codyjevem nima } \\
\text { primernega odnosa do } \\
\text { Codyjevega idola Capla. } \\
\text { Tank je podoben } \\
\text { cesarskim pingvinom, } \\
\text { Cody pa je v primerjavi } \\
\text { z njim precej manjši. }\end{array}$ & $\begin{array}{l}\text { Gre za ironijo kot najbolj sistematični } \\
\text { način nepristnega govorjenja v smislu } \\
\text { maksime kakovosti: navesti kaj kot } \\
\text { res(nico) (von Polenz 1988: 314), } \\
\text { torej najočitnejši način izkoriščanja te } \\
\text { maksime. Ironija je prijazen način biti } \\
\text { napadalen. Tank Codyja napade na način, } \\
\text { ki očitno ne nasprotuje načelu vljudnosti. } \\
\text { V izvirniku in podnapisanem je Tank } \\
\text { zbadljiv, a ne žaljiv. To pa ne drži v } \\
\text { celoti za govorjeno, saj je z izrečenim Če } \\
\text { prdnem, te odnese žaljiv, kar potrjujejo } \\
\text { okoliščinske informacije, tj. razlika v } \\
\text { velikosti obeh pingvinov. Ilokucijska moč } \\
\text { izrečenega se tako spremeni. }\end{array}$ \\
\hline $\begin{array}{l}\text { /.../ } \\
\text { because } \\
\text { you'll } \\
\text { want to } \\
\text { watch } \\
\text { it over } \\
\text { and over } \\
\text { and over } \\
\text { again. }\end{array}$ & $\begin{array}{l}\text { /.../ ker me } \\
\text { boste hoteli } \\
\text { gledati } \\
\text { stokrat in } \\
\text { stokrat. }\end{array}$ & $\begin{array}{l}\text { /.../ hotl } \\
\text { gledati } \\
\text { naprej } \\
\text { in nazaj, } \\
\text { naprej in } \\
\text { nazaj, kr } \\
\text { naprej ... }\end{array}$ & $\begin{array}{l}\text { Sporočevalec Cody tako } \\
\text { utemelji ustvarjalcem } \\
\text { dokumentarnega filma, } \\
\text { zakaj jim priporoča, da } \\
\text { posnamejo njegov prvi } \\
\text { dvoboj s Tankom. }\end{array}$ & $\begin{array}{l}\text { V izvirniku rabljena besedna zveza over } \\
\text { and over and over again (vedno znova } \\
\text { in znova) je poslovenjena na dva različna } \\
\text { načina: stokrat in stokrat; naprej in nazaj, } \\
\text { naprej in nazaj, kar naprej. Pri slednjim } \\
\text { je zaradi kopičenja naprej in nazaj } \\
\text { dosežen večji učinek stopnjevanja. Tako } \\
\text { se poveča še učinek smešnega, saj se to, } \\
\text { za kar Cody meni, da bo zaradi nedvomne } \\
\text { kvalitete vredno ogleda, sprevrže v } \\
\text { svoje nasprotje, tj. v popoln polom. Zdi } \\
\text { se, da je ilokucijska moč v izvirniku in } \\
\text { pri govorjenem enaka, šibkejša pa pri } \\
\text { podnapisanem. }\end{array}$ \\
\hline $\begin{array}{l}\text { I just } \\
\text { pointed } \\
\text { you in } \\
\text { a direc- } \\
\text { tion. }\end{array}$ & $\begin{array}{l}\text { Samo prav } \\
\text { sem te } \\
\text { usmeril. }\end{array}$ & $\begin{array}{l}\text { Sam na } \\
\text { prav tir } \\
\text { sem te } \\
\text { naglihal. }\end{array}$ & $\begin{array}{l}\text { Sporočevalec je Capl, } \\
\text { prejemnik pa Codyji. }\end{array}$ & $\begin{array}{l}\text { Gre za primer reagiranja na pohvalo/ } \\
\text { zahvalo, ko naj bi naslovnik (Capl) } \\
\text { glede na Leechevo vljudnostno načelo } \\
\text { in njegovi maksimi skromnosti in } \\
\text { odobravanja zmanjšal hvalo 'jaza' in } \\
\text { zvečal hvalo 'drugega'. Z izrazi tir in } \\
\text { naglihati, po SSKJ opredeljenim kot } \\
\text { nižje pogovorno, se zdi Caplova reakcija } \\
\text { pristnejša, s čimer se spremeni ilokucijska } \\
\text { moč izrečenega. }\end{array}$ \\
\hline $\begin{array}{l}\text { I can } \\
\text { feel it in } \\
\text { my nug- } \\
\text { gets. }\end{array}$ & $\begin{array}{l}\text { Na vodi ga } \\
\text { čutim. }\end{array}$ & $\begin{array}{l}\text { Čutim } \\
\text { ga na } \\
\text { bedrcah. }\end{array}$ & $\begin{array}{l}\text { Sporočevalec je } \\
\text { petelinček Joe. }\end{array}$ & $\begin{array}{l}\text { V izvirniku in govorjeno gre za } \\
\text { aktualizacijo frazema to feel in one’s } \\
\text { bones oz. čutiti ga na vodi, aktualizacije } \\
\text { v podnapisanem ni. Ilokucijska moč je } \\
\text { spremenjena. }\end{array}$ \\
\hline $\begin{array}{l}\text { No, } \\
\text { no, not } \\
\text { really. }\end{array}$ & $\mathrm{Ne}$, niti ne. & $\begin{array}{l}\text { Ja ne, no. } \\
\text { Niti ne. }\end{array}$ & $\begin{array}{l}\text { Sporočevalec je } \\
\text { petelinček Joe, ki ne } \\
\text { rad prizna, da ne ve } \\
\text { natanko, o kom govori } \\
\text { Cody. }\end{array}$ & $\begin{array}{l}\text { Govorjeno se bolj približa načinu } \\
\text { govorjenja med ožjeinteresnimi } \\
\text { dvogovori, saj sporočevalec z } \\
\text { diskurzivnim usmerjevalcem ja izrazi } \\
\text { sicer strinjanje, takoj nato pa strinjanje } \\
\text { zanika s členkom ne in svojo zadrego } \\
\text { izrazi še z medmetom no. Šele na to sledi } \\
\text { pravi odgovor na vprašanje, pa še ta je } \\
\text { omiljen s členkom niti. V podnapisanem } \\
\text { bi verjetno bil dosežen enak učinek, če bi } \\
\text { prevajalec kopičil, tj. vsaj enkrat stično } \\
\text { ponovil, členek } n e \text {. }\end{array}$ \\
\hline
\end{tabular}




\begin{tabular}{|c|c|c|c|c|}
\hline $\begin{array}{l}\text { He's a } \\
\text { dirty } \\
\text { trashcan } \\
\text { full of } \\
\text { poop. }\end{array}$ & $\begin{array}{l}\text { Napihnjen } \\
\text { kup dreka } \\
\text { je. }\end{array}$ & $\begin{array}{l}\text { On je en } \\
\text { drekec } \\
\text { pekec. }\end{array}$ & $\begin{array}{l}\text { S temi besedami } \\
\text { pingvinček Arnold } \\
\text { označi Tanka. }\end{array}$ & $\begin{array}{l}\text { Tako podnapisano kot govorjeno se } \\
\text { odmakne od sporočenega v izvirniku: } \\
\text { Umazan smetnjak je, poln kakca. } \\
\text { Pri govorjenem gre za aktualizacijo } \\
\text { naslova družabne igre Ekec Pekec } \\
\text { Kurji drekec. Zaradi pomanjševalnic } \\
\text { v izvirniku in pri govorjenem, ki } \\
\text { umilijo kritiko, je tu ilokucijska moč } \\
\text { nespremenjena. }\end{array}$ \\
\hline $\begin{array}{l}\text { I'm not } \\
\text { touching } \\
\text { you. Not } \\
\text { touching } \\
\text { you. }\end{array}$ & $\begin{array}{l}\text { Ne bom se } \\
\text { te dotaknil. } \\
\text { Ne bom se } \\
\text { te dotaknil. }\end{array}$ & $\begin{array}{l}\text { Sploh te } \\
\text { ne šlatam. } \\
\text { Nič ti ne } \\
\text { delam. } \\
\text { Nič. }\end{array}$ & $\begin{array}{l}\text { Sporočevalec je } \\
\text { Codyjev brat Glen, ki se } \\
\text { v času izrekanja Codyja } \\
\text { dotika. }\end{array}$ & $\begin{array}{l}\text { V izvirniku in pri govorjenem sta } \\
\text { glagola v (nedovršnem) sedanjiku, } \\
\text { v podnapisanem pa v prihodnjiku. } \\
\text { Razmerje med glagoloma šlatati ( } \\
\text { SSKJ z oznako nižje pogovorno) } \\
\text { in delati je enako razmerju med } \\
\text { podpomenko in nadpomenko, s čimer } \\
\text { se pomensko polje razširi. V izvirniku } \\
\text { sporočevalec s pomočjo paralelizma } \\
\text { stopnjuje učinek izrečenega - temu } \\
\text { sledi tudi podnapisano -, v govorjenem } \\
\text { pa se učinek stopnjuje z razširitvijo } \\
\text { pomenskega polja s šlatati na delati } \\
\text { in s členka sploh - izraža veljavnost } \\
\text { za celoto v primerjavi z njenimi deli } \\
\text { - na nikalni zaimek nič, ki izraža } \\
\text { neobstajanje. Uporabljena tožilniška } \\
\text { oblika namesto rodilniške je pogostejša } \\
\text { v govorjenih sporočilih. }\end{array}$ \\
\hline
\end{tabular}

Spremenjena ilokucijska moč sporočenega je opazna in zaradi vplivanja na predstavitev posameznih likov tudi moteča $\mathrm{v}$ animiranem filmu Ninja želve. $\mathrm{V}$ izvirniku in podnapisanem Max Winters ogovorjenega zgolj vpraša po imenu: What's your name? oz. In kako je pa tebi ime?; v govorjenem se $\mathrm{z}$ izrekom Čigav si pa ti? postavi hierarhično više. Ilokucijska moč sporočenega je tako spremenjena.

Pri uspešnosti prevoda je treba izpostaviti še vprašanje (ne)potrebnosti prevajanja besedil pesmi, npr. v filmu Divji valovi in v Avtomobilih. Če izhajamo iz dejstva, da izrečeno in vse drugo sooblikuje sporočeno, potem je upravičena zahteva po prevajanju besedil pesmi, saj le-te pogosto ubesedijo okoliščinski tip informacije. Npr. v risanem filmu Divji valovi v prizoru 11 Cody ne ve, katero pot naj izbere, sicer se odpravi po poti, ki mu jo pokaže Capl, a se vrne na izhodiščno točko. Besedilo pesmi je jasno: Ne vem, kam naj grem. Preveč se bojim, da opeklin ne dobim ... (I don't know which way I should turn. I'm too afraid of getting burn ....). ${ }^{3}$

${ }^{3}$ Zanimivo je, da je v omenjenem risanem filmu prevedena pesem, ki jo poje Capl v prizoru 21. 


\subsection{Uspešnost sinhronziranja - uspešnost poustvarjanja ožjeinteresnih govornih dogodkov}

Moje osrednje zanimanje je namenjeno vprašanju, kako uspešno skušajo slovenski ustvarjalci posneti pravzaprav ožjeinteresne govorne dogodke. To pomeni poznavanje, upoštevanje ali vključevanje leksikalnih, oblikoslovnih, glasoslovnih (družbenostne zvrsti jezika), skladenjskih in drugih značilnosti slovenskih govorjenih ter tudi drugih sporočil, npr. komentiranja športnih dogodkov (Divji valovi, Avtomobili), kritike oz. ocene restavracij (Ratatouille) glede na kulturno, družbeno in drugače specifičnega naslovnika.

\subsubsection{Družbenostne zvrsti jezika}

Leksikalne, oblikoslovne in glasoslovne značilnosti kot posledice izkoriščanja različnih neknjižnih družbenostnih zvrsti jezika (sociolektov) v posameznih filmih prikazujeta tabeli 2 in 3.

Tabela 2: Ratatouille

\begin{tabular}{|c|c|c|c|}
\hline Lik & Glas (AN/SL) & Izvirnik & $\begin{array}{l}\text { Slovensko (v oklepaju } \\
\text { podnapisano) }\end{array}$ \\
\hline Remy & P. Oswalt/L. Bizovičar & & $\begin{array}{l}\text { Osrednji slovenski pogovorni } \\
\text { jezik, pri pripovedovanju bliže } \\
\text { zbornemu jeziku. }\end{array}$ \\
\hline $\begin{array}{l}\text { Emile, Remyjev } \\
\text { brat }\end{array}$ & P. Sohn/V. Belšak & & $\begin{array}{l}\text { Štajerski, bolj mariborski } \\
\text { pogovorni jezik, npr. Če te bo } \\
\text { ata vido, bo močno jezen. }\end{array}$ \\
\hline $\begin{array}{l}\text { Django, } \\
\text { Remyjev oče }\end{array}$ & B. Dennehy/I. Valič & & $\begin{array}{l}\text { Štajerski, mariborski pogovorni } \\
\text { jezik, več stereotipov za to } \\
\text { jezikovno zvrst, npr. idi beg; ne } \\
\text { nea; gremo f čolne. }\end{array}$ \\
\hline $\begin{array}{l}\text { Šef Skinner, } \\
\text { Collete, Gusteau }\end{array}$ & $\begin{array}{l}\text { I. Holm/B. Završan, } \\
\text { J. Garofalo/N. Ivanič, } \\
\text { B. Garrett/B. Cavazza }\end{array}$ & $\begin{array}{l}\text { Francoski naglas, } \\
\text { značilna izgovarjava r. }\end{array}$ & $\begin{array}{l}\text { Francoski naglas, značilna } \\
\text { izgovarjava r. }\end{array}$ \\
\hline Linguini & L. Romano/M. Javšnik & Ameriški, nevtralno. & Nevtralno. \\
\hline Horst & W. Arnett/M. Potrč & $\begin{array}{l}\text { Rahel nemški naglas, } \\
\text { npr. Ja. }\end{array}$ & Nemškega naglasa ni opaziti. \\
\hline Mustafa & $\begin{array}{l}\text { J. Ratzenberger/V. } \\
\text { Dragan }\end{array}$ & $\begin{array}{l}\text { Angleščina azijskih, } \\
\text { verjetno indijskih } \\
\text { priseljencev. }\end{array}$ & $\begin{array}{l}\text { Slovenščina priseljencev iz } \\
\text { bivše Jugoslavije, npr. Što su } \\
\text { ovi korn dogi? (Kaj so koruzne } \\
\text { hrenovke?). }\end{array}$ \\
\hline
\end{tabular}

Iz tabele 3 je razvidno, da člani iste družine govorijo različne sociolekte, kar pa ni posledica starostnih razlik, ampak prej svetovnonazorskih.

${ }^{4}$ Django je tipično starševski lik: s svojega vidika pametnimi nasveti skuša pomagati Remyju. 
Tabela 3: Avtomobili

\begin{tabular}{|c|c|c|c|}
\hline Lik & Glas (AN/SL) & Izvirnik & Slovensko (v oklepaju podnapisano) \\
\hline $\begin{array}{l}\text { Lightning/Strela } \\
\text { McQueen }\end{array}$ & O. Wilson/P. Forte & & $\begin{array}{l}\text { Ljubljansko, brez tonemskosti, npr. jas; } \\
\text { mislem; hotu sem; tkole; kokar. }\end{array}$ \\
\hline Mater/Dajz & $\begin{array}{l}\text { L. The Cable Guy/ G. } \\
\text { Lešnjak }\end{array}$ & & $\begin{array}{l}\text { Dolenjsko, sliši se tonemskost, npr. } \\
\text { nabere v odpadnem bloki, druzga, kəga } \\
\text { je, niač. }\end{array}$ \\
\hline Ramone & Ch. Marin/B. Završan & $\begin{array}{l}\mathrm{Z} \text { mehiškim } \\
\text { naglasom }\end{array}$ & $\begin{array}{l}\text { Slovenščina priseljencev iz bivše } \\
\text { Jugoslavije, npr. Če pa rabeš barvu, } \\
\text { Ramon bo to vse zrihtu. Ej, samo ti reci } \\
\text { kaj bi, veš, pa to pa sploh ne ...; A maš } \\
\text { rad ćrte do van Dača? }\end{array}$ \\
\hline Luigi & T. Shalhoub/M. Žorž & & $\begin{array}{l}\text { Sicer knjižno, a šumnikov ne izgovarja, } \\
\text { namesto njih sičniki, npr. Aha, haha, ne } \\
\text { morem verjeti. Stiri nove gume! Gracie. }\end{array}$ \\
\hline Guido & $\begin{array}{l}\text { G. Quaroni/D. De } \\
\text { Girolamo }\end{array}$ & Italijansko & $\begin{array}{l}\text { Brez prevoda, italijansko tudi v } \\
\text { slovenščini. }\end{array}$ \\
\hline $\begin{array}{l}\text { Bob Cutlass/Bor } \\
\text { Sotlar }\end{array}$ & B. Costas/J. Mastnak & & $\begin{array}{l}\text { Imitacija znanega slovenskega športnega } \\
\text { komentatorja dirk formule } 1 \mathrm{M} \text {. Alešiča. }\end{array}$ \\
\hline $\begin{array}{l}\text { Darrell Cartrip/ } \\
\text { Dare Karting }\end{array}$ & D. Waltrip/M. Potrč & & $\begin{array}{l}\text { Štajersko, mariborsko, npr. pubec; Batof; } \\
\text { /... je mislo, da je toto njegovo leto, da } \\
\text { bo končno stopo ...; po takem postanki; } \\
\text { fertik; ftrgalo. }\end{array}$ \\
\hline $\begin{array}{l}\text { Kori Turbowitz/ } \\
\text { Lori Turbović }\end{array}$ & S. Clark/H. Petelin & & $\begin{array}{l}\text { Mežiško koroško, npr. nəč novega; } \\
\text { Hwala, da ste klicali.; Erbus, a ste vi } \\
\text { Dohtar?; Čujte, ka ... }\end{array}$ \\
\hline
\end{tabular}

V Avtomobilih jezikovna zvrst kaže na karakterne značilnosti likov, ki ne govorijo osrednjega slovenskega pogovornega jezika. Ti liki so svetovnonazorsko malo omejeni, a v svojem bistvu preprosti, srčni in dobri (Dajz). Vprašljiva pa je raba neknjižne zvrsti pri novinarki Lori Turbović in športnem komentatorju Daretu Kartingu, saj naj bi si ti prizadevali govoriti knjižno.

V animiranem filmu Divji valovi je opazna deskarska slengovska govorica. Ekscesnost se kaže v: a) rabi značilnih slengovsko obarvanih izrazov, npr. Kva dogaja za Živjo, b) pogosti rabi prevzetih besed, c) večji ekspresivnosti rabljenih leksemov, č) priložnostnih tvorjenkah in d) hotenem kršenju jezikovne norme, npr. blo bo brutalno. Tako se angleški/ameriški slengovsko rabljeni izrazi kot dude, bro (brother,) man slovenijo kot model, stari, kolega, brat(ec). ${ }^{5}$ Njihova pogostost je odvisna od kanala: v govorjenem se namesto dude večkrat pojavi model in redko stari, pri podnapisanem je pogostejši stari; bro in man se v podnapisanem slovenita s kolega, v govorjenem pa z brat(ec). Poleg (nižje) pogovornih splošno znanih prevzetih besed, npr. cajt, štekati, nucati, kušniti, šlatati, probati, britof; ful, kul, se pojavljajo še novejše, večinoma iz angleščine prevzete besede, npr. sfrizniti, luzer, izi, srf, srfer, srfanje. Iz besede srf-pogosta sopomenka v govorjenem je dilca, redko bord/bort - sta nastali priložnostni

\footnotetext{
${ }^{5} \mathrm{~V}$ prizoru, v katerem petelinček Joe začne iskati Codyja, petelinček v izvirniku z man ogovori galeba, v slovenskem prevodu je podnapisano kolega, govorjeno pa peresni brat. To je glede na ogovorjenega izvirnejše in ustreznejše.
} 
tvorjenki srfenstvo in srfišče, slednja le v primeru odsrfati v večna srfišča. Obe tovrstni tvorjenki se pojavljata le pri govorjenem, pri podnapisanem je namesto srfenstvo rabljena besedna zveza tekmovanje $v$ deskanju, namesto odsrfati v večna srfišča pa zelo redki so se vrnili. Priložnostna tvorjenka je tudi kot žaljivka rabljen leksem kretank, nastal kot sklop iz okrajšav besed kreten in Tank (ime lika) verjetno po angl. zgledu skank; v podnapisanem slovenjen s smrduh. Značilna slengovska ekspresivnost je v govorjenem izrazitejša kot $\mathrm{v}$ podnapisanem.

Poleg angleških prevzetih besed se pri sinhronizaciji filma Divji valovi, torej ne v izvirniku, prevzemajo besede iz drugih jezikov, npr. nemščine, italijanščine: Bit morš u über ful super ekstra previden; ${ }^{6}$ Tri, dva, ena, vege.

V Ninja želvah (tabela 4) izstopajo imitacije, ki jih lahko razumemo kot nebesedilni, okoliščinski tip namigovanja (o besedilnem namigovanju glej dalje). Jure Mastnak posnema način govorjenja trenutnega ljubljanskega župana Zorana Jankovića (v vlogi Splinterja, očeta in učitelja osrednjih likov) in bivšega predsednika vlade Janeza Janše v vlogi glavnega negativca Maxa Wintersa.

Tabela 4: Ninja želve

\begin{tabular}{|l|l|l|}
\hline Nekateri liki & Glas (AN/SL) & Slovensko \\
\hline Master Splinter & Mako/J. Mastnak & $\begin{array}{l}\text { Govori kot Z. Janković, tj. ljubljansko s srbskim } \\
\text { naglasom. }\end{array}$ \\
\hline Raphael & N. North/J. Kuntner & Osrednjeslovensko, pogovorno. \\
\hline Karai & Z. Zhang/M. Berginc & Knjižno, zborno, a deluje togo. \\
\hline Max Winters & P. Stewart/J. Mastnak & $\begin{array}{l}\text { Govori kot J. Janša, tj. dolenjsko s tonemskim } \\
\text { naglasom. }\end{array}$ \\
\hline
\end{tabular}

Na zgoščenki Mitološki junaki pravljic ni možnosti poljubnega kombiniranja jezikov (angleščine in slovenščine), na voljo je le tonski zapis v slovenščini, tj. le govorjeno. Prav tako ni podatkov ${ }^{8}$ o govorcih posameznih likov, zdi se celo, da svoj glas več likom posodi ista oseba. Govorijo sicer v knjižni slovenščini, vendar z malo značilnostmi govorjenih besedil. V primerjavi z ostalimi analiziranimi filmi je tu slabša celotna produkcija: tonski zapis se ne ujema $\mathrm{z}$ video zapisom, npr. v pravljici Sinbad pomorščak lik na posnetku že kašlja, zvok pa sledi šele, ko na sliki lik ne kašlja več. Podobno je s premikanjem ustnic. Zato in zaradi velike podobnosti bolj monotonih glasov včasih ni jasno, kateri lik pravzaprav govori. Ta sinhronizacija tako naslovnika ne pritegne, da bi zgodbi sledil do konca.

\footnotetext{
${ }^{6}$ Primer je zanimiv tudi zaradi skladenjske zgradbe; gre za strukturni preskok, saj se s skladenjskega vidika izrečeno konča drugače, kot je bilo začeto, medtem ko se pomenska teža prenese na novo oblikovani del izrečenega.

${ }^{7} \mathrm{~V}$ Avtomobilih omenjeni imitator posnema Mirana Alešiča.

${ }^{8}$ Te podatke sem iskala tudi na spletni strani odgovornih za tonski zapis, tj. Mediafilm.
} 


\subsubsection{Skladenjske in druge značilnosti govorjenih sporočil}

Vključevanje neknjižnih zvrsti jezika pa ni edina posebnost govorjenih sporočil. Razlike med govorjenimi in zapisanimi sporočili se kažejo tudi na skladenjski ravni. ${ }^{9} \mathrm{~V}$ izvirniku so te razlike med govorjenim in podnapisanim redkejše kot v slovenščini. Večinoma so omejene na: a) kopičenja vprašalnic: [What], ${ }^{10}$ what you want is ...; in začetnikov ter diskurzivnih usmerjevalcev: [You know], it takes patience and finesse, b) vračanja: [A] I don't know [I guess ...], redko c) spreminjanje ilokucijske moči izrečenega, npr. zapisano je: Here, take it. Go ahead, izrečeno pa: You take it. Take it. Go ahead.

Tabela 5 prikazuje nekatere skladenjsko odvisne razlike med podnapisanim in govorjenim v animiranih filmih Divji valovi in Ratatouille kot posledice kopičenja, lahko sopojavljanja členkov, rabe začetnikov oz. diskurzivnih usmerjevalcev in nedokončanih skladenjskih zgradb.

Tabela 5: Razlike v skladenjski zgradbi med podnapisanim in govorjenim

\begin{tabular}{|l|l|l|l|}
\hline & Podnapisano & Govorjeno & Komentar \\
\hline $\begin{array}{l}\text { Divji } \\
\text { valovi }\end{array}$ & $\begin{array}{l}\text { Ne. Še eno priložnost } \\
\text { mi daj. }\end{array}$ & $\begin{array}{l}\text { Ne, ne, ne. Čakte, čakte. Sam } \\
\text { še eno priložnost mi dajte ... }\end{array}$ & $\begin{array}{l}\text { V govorjenem se kopičita nikalni } \\
\text { členek ne (gre za sopojavljanje } \\
\text { členka) in začetniško rabljeni } \\
\text { velelnik glagola čakati. Opazimo } \\
\text { lahko še razliko pri nanašanju na } \\
\text { ogovorjenega, v podnapisanem } \\
\text { je rabljen glagolskokončniški } \\
\text { morfem za drugo osebo ednine, } \\
\text { govorjenem za množino (tikanje } \\
\text { :vikanje). Tri pike označujejo } \\
\text { govorčevo željo, da bi še lahko } \\
\text { kako prepričal sogovorca, a } \\
\text { sprevidi, da je vse zaman. }\end{array}$ \\
\hline $\begin{array}{l}\text { Resničnostne šove } \\
\text { snemamo. }\end{array}$ & $\begin{array}{l}\text { Ja, mi pač snemamo } \\
\text { dokumentarc o vas, ne. }\end{array}$ & $\begin{array}{l}\text { V govorjenem se poleg začetnika } \\
\text { ja, pojavi še pogovorni vprašalni } \\
\text { členek ne. Zanimiva je raba } \\
\text { prvoosebnega množinskega } \\
\text { zaimka v imenovalniku in členka } \\
\text { pač. Kot sopomenki, čeprav to } \\
\text { nista, se pojavljata besedni zvezi } \\
\text { dokumentarc in resničnostni šov. }\end{array}$ \\
\hline Ni treba, saj so lahka. & $\begin{array}{l}\text { Glej, glej, glej, ni treba. Sej } \\
\text { so lahka. Res. }\end{array}$ & $\begin{array}{l}\text { V govorjenem izstopata } \\
\text { sopojavljanje začetniško } \\
\text { rabljenega velelnika gl. gledati } \\
\text { in po SSKJ medmetno rabljenega } \\
\text { res. }\end{array}$ \\
\hline
\end{tabular}

${ }^{9}$ Moj izhodiščni namen je bil, da bi pokazala na razlike med podnapisanim in govorjenim na vseh jezikovnih ravneh. A poskus ločevanja ob zavedanju, da izbrana leksika lahko pogojuje skladenjske vzorce, ni obrodil sadov, saj zgolj naštevanje razlik med zapisanim in govorjenim v leksiki, npr. sladkor : cuker, ali ugotavljanje slovnične pravilnosti oz. nepravilnosti, npr. /.../ kaj bom bil, ne daje celotne podobe.

${ }^{10} \mathrm{~V}$ oglatem oklepaju je dodano tisto govorjeno, ki je drugačno od podnapisanega. 


\begin{tabular}{|c|c|c|c|}
\hline & $\begin{array}{l}\text { Naphan sem s tabletami } \\
\text { proti migreni. }\end{array}$ & $\begin{array}{l}\text { A veste, da sn čist nabasan s } \\
\text { tabletam proti migreni. }\end{array}$ & $\begin{array}{l}\text { V govorjenem govoreči z } \\
\text { glagolom vedeti v vlogi } \\
\text { napovedovalnega začetnika } \\
\text { kot jedra glavnega stavka } \\
\text { in s prenosom pomenske } \\
\text { teže na predmetni odvisnik } \\
\text { skuša vzbuditi zanimanje pri } \\
\text { sogovorcu. Ekspresivnost je } \\
\text { v obeh prevodih dosežena } \\
\text { na različne načine: pri } \\
\text { govorjenem s prislovom } \\
\text { čist }(o) \text { za izražanje odsotnosti } \\
\text { kakršne koli omejitve in po } \\
\text { SSKJ s kvalifikatorjem pog. } \\
\text { označenim glagolom nabasati } \\
\text { se v pomenu 'zelo se najesti'; } \\
\text { v podnapisanem pa z vedno } \\
\text { redkeje rabljenim glagolom } \\
\text { naphati. }\end{array}$ \\
\hline & $\begin{array}{l}\text { Škoda, da nisi prišel } \\
\text { včeraj. Super valove smo } \\
\text { imeli. }\end{array}$ & $\begin{array}{l}\text { Veste ... Ej, škoda, da vas } \\
\text { ni blo včeri, super valove } \\
\text { smo mel. }\end{array}$ & $\begin{array}{l}\text { Tudi v tem primeru se kot } \\
\text { začetnik pojavlja glagol } \\
\text { vedeti. Govoreči začeto } \\
\text { strukturo opusti in z novim } \\
\text { začetnikom, tj. medmetom } \\
\text { ej, začne nov izrek, v } \\
\text { katerem lahko za razliko od } \\
\text { podnapisanega opazimo rabi } \\
\text { drugoosebnega množinskega } \\
\text { zaimka vas in ustreznega } \\
\text { glagolskokončniškega morfema } \\
\text { (vikanje). }\end{array}$ \\
\hline \multirow[t]{2}{*}{ Ratatouille } & $\begin{array}{l}\text { Vem, da bi moral } \\
\text { sovražiti ljudi, vendar so } \\
\text { nekaj posebnega. }\end{array}$ & $\begin{array}{l}\text { Mmm, vem, da bi moral } \\
\text { ljudi sovražit, ampak, ampak, } \\
\text { ampak nekej je na njih ... }\end{array}$ & $\begin{array}{l}\text { S kopičenjem protivnega } \\
\text { veznika ampak govoreči } \\
\text { nakazuje svojo stisko. }\end{array}$ \\
\hline & $\begin{array}{l}\text { Pariz? Ves ta čas sem bil } \\
\text { pod Parizom? } \\
\text { Vau. } \\
\text { Lep je. }\end{array}$ & $\begin{array}{l}\text { Pariz? Ves ta cajt sem se skril } \\
\text { pod Pariz? } \\
\text { Uau. } \\
\text { Pa sej to je ... to je čudovito. }\end{array}$ & $\begin{array}{l}\text { V govorjenem z vračanjem } \\
\text { oz. kopičenjem to je ... to je } \\
\text { govorec jasneje in močneje } \\
\text { kaže na svoja čustva ob } \\
\text { ugotovitvi, kje je. To morda } \\
\text { potrjujejo tudi napake na } \\
\text { oblikoslovni in leksemski ravni. }\end{array}$ \\
\hline
\end{tabular}

Kot tipična skladenjska značilnost govorjenih sporočil se pojavljajo vrivki, npr. Inn, znaš še kaj - mislim - poleg srfanja? (Divji valovi), ter paralelizem, npr. Nočem ga na svojem sodišču in nočem ga v mestu. (Avtomobili). Slednji večinoma $\mathrm{v}$ funkciji stopnjevanja učinka izrečenega.

Povedne okrajšave so pogostejše $\mathrm{v}$ govorjenem kot podnapisanem, tako npr. športni komentator v Divjih valovih pravi: Sekunda molka., podnapisano pa je: Posvetimo jim trenutek tišine.

Tvorčeva namera je $\mathrm{v}$ podnapisanem in govorjenem ekvivalentno izražena. Izreka, ki se pojavljata kot slovenska prevoda istega angleškega izreka, sta medsebojno zamenljiva (tabela 6), pri čemer se zdi, da so v govorjenem rabljeni izreki s prvinami, značilnejšimi za neknjižne zvrsti jezika. 
Tabela 6: Pomenska ekvivalentnost, dosežena z različnimi skladenjskimi strukturami

\begin{tabular}{|c|c|c|}
\hline Film/odlomek v izvirniku & Podnapisano & Govorjeno \\
\hline \multicolumn{3}{|l|}{ Divji valovi } \\
\hline \multirow[t]{3}{*}{$\begin{array}{l}\text { [What] what you want is } \\
\text { something in between. Trust me. } \\
\text { I'm the expert here, okay? }\end{array}$} & $\begin{array}{l}\text { Torej bi rad nekaj vmes. Zaupaj } \\
\text { mi. Strokovnjak sem. }\end{array}$ & $\begin{array}{l}\text { Ti bi ..., ti bi rad nekaj vmes. } \\
\text { Verjem mi. Jaz sem strokovnjak. } \\
\text { Okej? }\end{array}$ \\
\hline & Sedemnajst jih imam. & Star sem sedemnajst let. ${ }^{11}$ \\
\hline & Pravega si vprašal. & $\begin{array}{l}\text { Jes sem ta prau naslov, mate } \\
\text { srečo. }\end{array}$ \\
\hline \multicolumn{3}{|l|}{ Ratatouille } \\
\hline & Prvič, nismo tatovi! & Prva stvar, mi NEA krademo! \\
\hline $\begin{array}{l}\text { Remy, you are better than that. } \\
\text { You are a cook. A cook makes. A } \\
\text { thief takes. You are not a thief. }\end{array}$ & $\begin{array}{l}\text { Remy, to nisi ti. Kuhar si. Kuhar } \\
\text { ustvarja, tat pa jemlje. Nisi tat. }\end{array}$ & $\begin{array}{l}\text { Remy, globoko si padel. Ti si } \\
\text { kuhar. Kuhar cvre, tat požre. Ti pa } \\
\text { nisi tat. }{ }^{12}\end{array}$ \\
\hline \multicolumn{3}{|l|}{ Avtomobili } \\
\hline & Kupite antene! & Super antenske žogce prodamo! ${ }^{13}$ \\
\hline $\begin{array}{l}\text { No, no, no! That won't be } \\
\text { necessary. Hey, hey, big fella! } \\
\text { Yeah, you in the red! I could use } \\
\text { a little hose down. Help me wash } \\
\text { this off. Where is his goin'now? }\end{array}$ & $\begin{array}{l}\text { Ne! Res ni treba. Ej, velikan! Ti } \\
\text { v rdečem! Cev bi mi prav prišla, } \\
\text { da bi tole malo opral. Kam pa } \\
\text { gre? }\end{array}$ & $\begin{array}{l}\text { Ne, ne, ne! To-le ni povsem } \\
\text { nujno. Hej, hej, veliki (nagovori } \\
\text { Rdečka)! Ja, ja, ti v rdečem. Cev } \\
\text { bi si sposodo, da bi tole malo pral. } \\
\text { Kam pa je šou zdaj (nagovori } \\
\text { Dajza)? }\end{array}$ \\
\hline My lucky sticker's all dirty. & Moja srečna nalepka je umazana. & Na srečni nalepki mam flek. \\
\hline $\begin{array}{l}\text { Nah, I'm just kiddin'. She just } \\
\text { likes me for my body. }\end{array}$ & $\begin{array}{l}\text { Hecam se. Samo moja karoserija } \\
\text { ji je všeč. }\end{array}$ & Hec. Pada na moja karoserija. \\
\hline
\end{tabular}

Razlike med podnapisanim in govorjenim so lahko v: a) besednem redu, npr. Življenje si mu rešila. oz. Rešila si ga iz vode pa to ... (Divji valovi), Emile je bil edini, ki je vedel za to. oz. Edini, ki je za to vedel, je bil Emile. (Ratatouille), b) pogostosti medmetov: Stari, to je porazno! oz. Ej! Ej, stari, to ni več res! (Avtomobili) in c) pogostosti ekspresivnih izrazov, ki jih je v govorjenem več kot v podnapisanem (tabela 7).

${ }^{11}$ Gl. imeti je tu rabljen s pomenskim poudarkom na pripisovanju lastnosti, stanja ipd. $\mathrm{komu} / \check{c} \mathrm{emu}$, in sicer je zapolnitev svojilnosti neposredno povezana z nosilcem lastnosti, stanja v vlogi osebka, gre za primer posebnega tipa, ki izraža prostorske, časovne in težnostne lastnosti koga/česa (Vidović Muha 2000: 260). Iz povedkovega določila dobimo pri pretvori zloženko je sedemnajstletni, torej je to primer časovne razsežnosti s sopomenko biti star.

${ }^{12} \mathrm{~V}$ izvirniku in govorjenem se izreka $A$ cook makes. A thief takes oz. Kuhar cvre, tat požre rimata.

${ }^{13}$ Vprašamo se lahko, ali je večja stopnja vljudnosti izkazana v podnapisanem ali govorjenem. Ker velelnost zmanjša vljudnost (kupite), je vljudnejša govorjena oblika, saj je upoštevana maksima radodarnosti: 'zvečaj škodo 'jaza' in zmanjšaj škodo 'drugega'. 
Tabela 7: Ekspresivnost v govorjenem je izrazitejša kot v podnapisanem

\begin{tabular}{|l|l|l|}
\hline Angleško & Podnapisano & Govorjeno \\
\hline O man, o man & Noro, noro. & O mater, o mater. \\
\hline $\begin{array}{l}\text { He's lost another tyre! King and } \\
\text { Chick are coming up fast! }\end{array}$ & $\begin{array}{l}\text { Izgubil je še eno! Kralj in Živec } \\
\text { se približujeta! }\end{array}$ & $\begin{array}{l}\text { Še eno mu je ftrgalo! Kralj pa } \\
\text { Živc pa ga žgeta proti njemu! }\end{array}$ \\
\hline $\begin{array}{l}\text { Boy, we ain't as dumb as you } \\
\text { thnik we are. }\end{array}$ & Nismo tako trapasti, kot misliš. & $\begin{array}{l}\text { Poba, smo manj butasti, kot si } \\
\text { misliš. }\end{array}$ \\
\hline
\end{tabular}

Določena stopnja ekspresivnosti je dosežena tudi z rabo frazemov (tabela 8).

Tabela 8: Frazemi v animiranem filmu Avtomobili.

\begin{tabular}{|l|l|l|l|l|}
\hline Lik & Angleško & Podnapisano & Govorjeno & Komentar \\
\hline Dare & $\begin{array}{l}\text { He's got it in the bag. } \\
\text { Call in the dogs and } \\
\text { put out the fire! We're } \\
\text { gonna crown us a new } \\
\text { champion! }\end{array}$ & $\begin{array}{l}\text { Zmago ima v } \\
\text { prtljažniku. Končajmo } \\
\text { lov na novega prvaka! } \\
\text { Okronali bomo novega } \\
\text { prvaka! }\end{array}$ & $\begin{array}{l}\text { Jaz mislim, da je že } \\
\text { zmago. Tekme je } \\
\text { fertik. Mi imamo pa } \\
\text { novega šampijona! }\end{array}$ & $\begin{array}{l}\text { Frazem: imeti zmago } \\
\text { žepu; aktualizacija } \\
\text { imeti zmago v } \\
\text { prtljažniku. }\end{array}$ \\
\hline $\begin{array}{l}\text { Šerif } \\
\text { Boy, you're in a heap }\end{array}$ & $\begin{array}{l}\text { Poba, čez streho si v } \\
\text { težavah. }\end{array}$ & $\begin{array}{l}\text { Poba, do strehe si v } \\
\text { godli. }\end{array}$ & $\begin{array}{l}\text { Frazem: čez glavo } v \\
\text { težavah vs. do glave } \\
\text { vežavah/godlji; } \\
\text { aktualizacija do strehe } \\
\text { / čez streho biti v } \\
\text { težavah/godlji }\end{array}$ \\
\hline Dajz & $\begin{array}{l}\text { I'd give my left two } \\
\text { nuts for somethin' } \\
\text { like that. }\end{array}$ & $\begin{array}{l}\text { Levo premo bi dal } \\
\text { za to. }\end{array}$ & $\begin{array}{l}\text { Jest bi dal vse, da bi } \\
\text { tole le počel. }\end{array}$ & $\begin{array}{l}\text { Frazem ledvico dati } \\
\text { za ... je aktualiziran v } \\
\text { levo premo dati za ... }\end{array}$ \\
\hline
\end{tabular}

\subsubsection{Besedilno, kulturno, družbeno in drugače pogojene razlike}

Razlike med podnapisanim in govorjenim so lahko pogojene $\mathrm{z}$ značilnostmi slovenskega prostora in časa. Tu mislim najprej primere besedilnega in okoliščinskega namigovanja (glej tudi zgoraj), pri katerih se morda upravičeno postavlja vprašanje, komu so animirani filmi namenjeni. ${ }^{14}$ Kot primere besedilnega in tudi nebesedilnega, okoliščinskega namigovanja razumem (tabela 9): a) vključevanje znanih slovenskih (ljudskih) besedil ali po tradiciji Slovencem znanih besedill ${ }^{15}$ in b) znanih izjav, namenjenih slovenski publiki, c) namigovanje na slovenska zemljepisna lastna imena, npr. naselbinska in imena jezer,

${ }^{14}$ Učinek medbesedilnosti v smislu namigovanja na znana besedila ali dejstva je odvisen od naslovnikovega vedenja. Tako je besedilno namigovanje v risanem filmu Avtomobili lahko ohranjeno le v podnapisanem, govorjenem pa ne. Npr. Float like a Cadillac, sting like a Beemer je primer namigovanja na izjavo boksa Joeja Lewisa: Float like a butterfly, sting like a bee, ohranjenega tudi v podnapisanem: Letim kot kadilak, pičim kot bemfelj (BMW), a ne v govorjenem: Drsim kot peresce, pičim kot raketa.

${ }^{15} \mathrm{~V}$ mislih imam znano pesem To mi radi skupine Crvena Jabuka. To mi deli bi lahko razumeli kot prevod refrena te pesmi To mi radi, to mi radi, jer ti možeš da mi radiš sve /.... 
č) oblikovanje primerjav v smislu lokalnih, slovenskih navad, kot je značilna malica po darovanju krvi.

Tabela 9: Besedilno in okoliščinsko namigovanje

\begin{tabular}{|c|c|c|c|}
\hline Film & Angl. & Podnaslovljeno & Govorjeno \\
\hline Ratatouille & $\begin{array}{l}\text { First. I'm a rat. Which } \\
\text { means life is hard. }\end{array}$ & & $\begin{array}{l}\text { Prvič, sem podgana. In če si } \\
\text { podgana, življenje ni cvetoče } \\
\text { polje. }\end{array}$ \\
\hline \multirow[t]{2}{*}{ Avtomobili } & $\begin{array}{l}\text { Uno for the money, due for } \\
\text { the show, tre to get ready, } \\
\text { and quattro to ... I can't } \\
\text { believe it. Go! }\end{array}$ & $\begin{array}{l}\text { Pripravljena, pozor ... Uno } \\
\text { za biznis, due za zabavo, tre } \\
\text { za kravo in quattro za ... To } \\
\text { je noro. Gremo! }\end{array}$ & $\begin{array}{l}\text { Pripravljena, pozor. Uno za } \\
\text { kelnarco, duo za kuharco, tre } \\
\text { pa za ljubico in quettro za ... } \\
\text { To je noro! Gremo! Gooo } \\
\text { hoohoho! }\end{array}$ \\
\hline & I can't imagine a better day. & $\begin{array}{l}\text { Lepšega dne si ne bi mogel } \\
\text { predstavljati. }\end{array}$ & To mi deli, skoz mi deli. \\
\hline \multirow[t]{3}{*}{ Divji valovi } & $\begin{array}{l}\text { You should know this. Tank } \\
\text { loves you. }\end{array}$ & $\begin{array}{l}\text { Povedati vama moram, da } \\
\text { vaju ima Tank zelo rad. }\end{array}$ & $\begin{array}{l}\text { Ej, a vesta, neki morta vedet. } \\
\text { Tank ma vas rad. }\end{array}$ \\
\hline & $\begin{array}{l}\text { And it's Maverick with this } \\
\text { new-school move. We'll call } \\
\text { it the Maverick. }\end{array}$ & $\begin{array}{l}\text { Ostal je Maverick z novo } \\
\text { figuro, ki ji bomo rekli kar } \\
\text { »maverick«. }\end{array}$ & $\begin{array}{l}\text { In Maverick skoči, kot da bi } \\
\text { bil } v \text { Planici. }\end{array}$ \\
\hline & & $\begin{array}{l}\mathrm{Z} \text { jezera Michigan. Tam } \\
\text { deskam. Edini v mestu sem } \\
\text { to počel. }{ }^{16}\end{array}$ & $\begin{array}{l}\text { Model, jes sem s Koseškega } \\
\text { barja. Jəs tam srfam. Jes sem } \\
\text { edini, ki to tam dela. }\end{array}$ \\
\hline \multirow[t]{2}{*}{ Avtomobili } & & $\begin{array}{l}\text { Moj odvetnik je nekje na } \\
\text { Tahitiju. }\end{array}$ & $\begin{array}{l}\text { Moj odvetnik je nekje } \mathrm{v} \\
\text { Portorožu. }\end{array}$ \\
\hline & $\begin{array}{l}\text { There's crowd of nearly } 200 \text {, } \\
000 \text { cars here at Los Angeles } \\
\text { International Speedway. } \\
\text { Tickets to this race are hotter } \\
\text { than a black leather seat on a } \\
\text { hot summer day! }\end{array}$ & $\begin{array}{l}\text { Množica skoraj } 200.000 \\
\text { avtov se je zbrala ob } \\
\text { mednarodni dirkalni stezi } \\
\text { Los Angelesa. Vstopnice so } \\
\text { bolj vroče kot črno usnje pri } \\
40 \text { stopinjah. }\end{array}$ & $\begin{array}{l}\text { Bob, danes se je na } \\
\text { losangelesko dirkališče } \\
\text { pripelajo skoro dvesto taužen } \\
\text { avtov. Karte za toto dirko pa } \\
\text { si ludi bol želijo ko kranjske } \\
\text { po krvodajalski akciji. }\end{array}$ \\
\hline
\end{tabular}

Kot primer namigovanja lahko razumemo tudi vključevanje znanih športnikov in športnih komentatorjev $\mathrm{k}$ sinhronizaciji filma. Tako $\mathrm{v}$ risanem filmu Divji valovi sodelujeta Igor E. Bergant in Dejan Košir. V vlogi snemalca dokumentarnega filma o Codyju pa nastopi Marko Potrč. Zanimivo je, da podnapisano sledi angleškemu izvirniku, saj lahko beremo Z nami je Sal Masekela v svetovni prestolnici deskanja, na otoku Pen Gu. in Kelly in Rob nam bosta povedala, kakšni izzivi čakajo deskarje.; na teh mestih pa lahko slišimo: $Z$ vami sem Igor E. Bergant v svetovni prestolnici deskanja na otoku Pen Gu. oz. Z nami sta Kelly in Rok. Hej Dejan, kakšni izzivi čakajo naše dskarje. V zadnjem primeru lahko opazimo neskladje, saj komentator pozdravlja Kellyja in Roka, nato pa se obrne k Dejanu, ki ga prej sploh ne omeni.

${ }^{16} \mathrm{~V}$ podnapisanem je glagol $\mathrm{v}$ pretekliku, $\mathrm{v}$ govorjenem pa $\mathrm{v}$ sedanjiku. 
Razlike med podnapisanim in govorjenim so lahko posledica umeščanja dela filmskih dogajanj v slovenski prostor in s tem težnje po približevanju slovenskim naslovnikom, pri tem lahko gre tudi za ironiziranje aktualnih družbenopolitičnih dogajanj, npr. v filmu Divji valovi lahko v izvirniku in podnapisih beremo: /.../ here on Pen gu Island. oz. /.../ iz zaliva Pen gu, to je sinhronizirano kot /.../ iz penguanskega zaliva, nekateri mu rečejo tudi srfarska vala.

Posledice razlik med podnapisanim in govorjenim so razlike $\mathrm{v}$ besedilnih nizih in nesovezno besedilo. Za ponazoritev razlik $\mathrm{v}$ besedilnih nizih navajam primer iz risanega filma Divji valovi. Tu v podnapisanem najdemo k nanašalnici kit sonanašalnici: ta debeluh sesalski in Moby Dick, v govorjenem pa ta kepa špeha in prav tako Moby Dick. V vseh primerih gre za parafrazo. Kot nesovezni del besedila lahko analiziramo primer neustrezne, nepričakovane reakcije na že izrečeno, ko se Lani z besedami Res si me. odzove na Codyjevo repliko Premagal sem te. (podnapisano) oz. Zmagal sem. (govorjeno).

Razlike med podnapisanim in govorjenim so posledice hotenega kršenja jezikovne norme kot značilnost ekscesnega sociolekta, npr. Blo bo brutalno. (Divji valovi), kot zavestno sledenje ustaljenega načina govorjenja ne glede na jezikovno normo, npr. A mi lahko, lepo prosim, kdo razloži zakaj se gre? (Avtomobili).

\section{Sklep}

Uspešnost sinhroniziranja izbranih animiranih filmov je odvisna od uspešnosti postavljanja tujejezičnega filma, tj. komunikacijskega stika, namenjenega neslovenskim naslovnikom, $\mathrm{v}$ slovenski prostor in slovenščino tako, da je film blizu slovenskim naslovnikom. Posledica tega »prilagajanja « besedilnega tipa in deloma tudi okoliščinskega tipa informacij - spremenijo se okoliščinske informacije, vezane na naslovnika - so razlike med izvirnikom, podnapisanim, ki praviloma bolj sledi izvirniku in upošteva slovensko jezikovno normo in predpis, ter govorjenim. Slednje se približuje načinu govorjenja »doma« oz. tvorjenju ožjeinteresnih dvogovorov, torej vključuje tako obrobne kot tudi ekscesne sociolekte, upošteva skladenjske značilnosti govorjenih besedil. Večja ekspresivnost govorjenega ni posledica le že omenjenega, ampak tudi številnih aktualizacij frazemov, besedilnega in okoliščinskega namigovanja, znanega pretežno slovenskim naslovnikom.

Zbrano gradivo tako na eni strani kaže premišljenost in skrbnost pri izbiri slovenskih glasov ter pri posnemanju ožjeinteresnega komunikacijskega stika, na drugi strani pa se kot izraziti pomanjkljivosti kažeta neusklajenost zvoka in slike ter enoličnost slovenskega glasu, ki lahko $\mathrm{v}$ istem animiranem filmu govori več likov. 


\section{LITERATURA}

Tomo KOROŠEC, 1998: Stilistika slovenskega poročevalstva. Ljubljana: Kmečki glas.

Irena KOVAČIČ, 1992: Jezikovni pogled na podnaslovno prevajanje televizijskih oddaj. Doktorska disertacija. Ljubljana.

- -, 1999: Podnaslovni prevod kot del polisemiotičnega besedila. Uporabno jezikoslovje. 7/8, 100-111.

Mira KRAJNC IVIČ, 2005: Besedilne značilnosti javne govorjene besede. Maribor: Zora 35.

- -, 2008: Zasebni dvogovori. Doktorska disertacija. Ljubljana.

Peter von POLENZ, 1988: Deutsche Satzsemantik. Grundbegriffe des Zwischenden-Zeilen-Lesens. Druga, pregledana izdaja. Berlin, NewYork.

Ada VIDOVIČ MUHA, 2000: Slovensko leksikalno pomenoslovje. Govorica slovarja. Ljubljana: Znanstveni inštitut Filozofske fakultete.

\section{A LINGUISTIC APPROACH TO THE SUCCESS OF SYNCHRONIZATION IN ANIMATED FILMS}

As a linguist, I try to comprehend the success of synchronization in animated films from the perspective of pragmatics and interactional sociolinguistics: the speaker/writer, director of an animatedfilm, as with writers and illustrators of picture books, is trying to communicate through characters, which in the originals often have voices provided by famous actors and actresses. By establishing a particular relation between two types of information - the linguistic and the contextual, which is considered a typical characteristic of spoken communication, an imaginative, and believable story is presented that is suitable for children. With such a story, he/she is trying to affect the recipients, the children, and the wider audience, so that they enjoy themselves and relax, or so that they find the moral of the story as motivation for solving their own problems. One could say that the function of animated films is poetic, and that's why it can beseen as partly comparable with the function of children's literature. For instance, the story of Peter Klepec, from F. Bevk, tells of a little child who gets supernatural powers to defeat the villains and to help those in need.

With synchronization, the contextual type of information remains unchanged, but the linguistic or textual type changes because the language code must change: instead of English, the Slovene language is used. The success of synchronization depends not only on the quality of translation from one language to another, but also on the quality of the interpreters, the Slovene actors, or speakers of the textual information.

For the purposes of analysis, I chose some recently produced foreign language animated movies, mostly in English: Cars (2006), Ratatouille (2007), Surf's Up (2007), Teenage Mutant Ninja Turtles (2007) and a compilation of the world's most beautiful tales: Mythological Heroes of Fairy Tales.

The material is divided into two groups, which show, on the one hand, the thoughtfulness and care taken in choosing Slovene voices and in imitating ordinary communication or 
approximating ordinary communication tailored to the individual interests of particular participants in both: two-way and one-way discourse. This also includes marginal and excessive sociolects. On the other hand, the collected material shows at least two imperfections: the lack of synchronization between sound and picture, and the vocal monotony of the Slovene actor, an effect which is even more pronounced if such an actor reads the part of more than one character. 